\title{
The Importance of Packaging and Graphic Design to Communicate Corporate Social Responsibility
}

\author{
Listia Natadjaja \\ Visual Communication Design Department, Faculty of Art and Design \\ Petra Christian University, Surabaya \\ E-mail: listia@petra.ac.id
}

\begin{abstract}
Graphic design's function develops through time. It does not only function to inform a product but also elements to communicate Corporate Social Responsibility. As happened in catastrophic areas in Indonesia like Aceh in 2004, Nias in 2005, Jogjakarta in 2007, Bekasi District in 2009, etc. many donated products had their contributor's information, especially the ones from corporations. There are many ways a company could implement their social responsibility. Graphic design cannot stand alone, it needs an effective media for its placement, one of them is packaging design. By using a Biskiz Susu packaging design as a case study, I try to analyze the design elements, like color, shape, brand, illustration/character, typography, and layout and then connect them with aspects like: the visual perception impact of packaging design and the importance in communicating Corporate Social Responsibility. For input information, I also discuss some consideration aspects of placing the contributor's identity on the packaging. Based on this study, the contributor's information in the products gives many advantages. The result shows that graphic design could be the effective element for communicating Corporate Social Responsibility and packaging design can be one of the recommended media for graphic design placement. Hopefully, this analysis could help a corporation, organization or the government in organizing the graphic design elements and considering a packaging as a medium to communicate Corporate Social Responsibility (CSR).
\end{abstract}

Keywords: Packaging design, graphic design, corporate social responsibility (CSR).

\section{Introduction}

\section{Background}

The tsunami in the Indian Ocean on 26 December 2004 killed at least 200,000 people in countries as far apart as Indonesia, Thailand, Sri Lanka and Somalia. Six months after the Asian tsunami, a leading international charity said the poorest victims had benefited the least from the massive relief effort. A survey by Oxfam found that aid had tended to go to businesses and landowners, exacerbating the divide between rich and poor. This poverty gap was worst in Aceh, the Indonesian province which was the most badly affected area, already impoverished by conflict before the tsunami hit. Half a million survivors were homeless. Another survey by a group of British academics monitoring the delivery of aid has found that, six months on, there was little evidence of permanent accommodation being built for most people. It says starkly that these failures would not be tolerated after a disaster in the developed world. All aid agencies, as well as regional governments must share some blame for this failure. The unprecedented international response to the tragedy means that the immediate humanitarian demands could be fully funded. Failure to deliver assistance effectively to the poorest, or to plan properly for the future, reveals fundamental weaknesses in the system. "There is a great deal of room for governments and aid agencies to work closer together" (J. Mehta, UK.).

No longer after Aceh tsunami, the massive earthquake struck Northern Sumatra in Indonesia on 28 March 2005. (Nias Earthquake, 2005). Then, the earthquake struck Jogjakarta in the morning of May 27, 2006. USGS estimated magnitude of this earthquake is $\mathrm{Mw}$ 6.3. More than 5,000 people have been killed and thousands more injured by a strong earthquake. (The May 27, 2006. Jogjakarta Earthquake).

The disaster that struck Indonesia gained worldwide concerns about our condition. A lot of national and international aids were directed to Aceh, Nias and Jogjakarta, including United Nations. Most of the help consisted of clothes, food, medical aid, etc. Among foods there were instant noodles, milk, canned goods, biscuits, etc. Many of the donated products had identities, to show relevant parties 
that sponsored them. Some of the identities were not permanent; the name of the company or the product was just put on the label, with big letters. The contributors' names were sometimes different than the products which were given, so they wrapped the product with another wrapping paper and then put a label on it. Everyone who received the package could know who helped them. On television, the identities of the contributors were in exchange broadcasted. It is a unique phenomenon these days. For common people, it might seem like a campaign or promotion but for the company it could identify as their Corporate Social Responsibility. Over the last decade, CSR has shifted from the margin to the mainstream of business practice. However, behind the apparently positive picture lie two problems that create impediment to companies in realising the potential benefits of CSR. The first problem arises from the fact that one of the greatest drivers causing business leaders to adopt CSR is 'fear', with emphasis on avoiding trouble than looking for opportunities. The second problem is that CSR is too often a 'bolt-on' to business operation rather than 'built in' to business strategy, resulting in CSR becoming a distraction and hindrance to business purpose and objectives, rather than a help. (Grayson, 2004:8).

Corporate Social Responsibility is the contribution that a company makes in society through its core business activities, its social investment and philanthropy programs, and its engagement in public policy. (Wineberg, 2004:72). CSR is a method where a company integrates its social responsibility and concern in its business operation and in its interaction to stakeholder based on voluntary and partnership principles. There are other names identical with Corporate Social Responsibility, like Corporate Giving/Charity, Corporate Philanthropy, Corporate Community/ Public Relation and Community Development. Those four names could be seen as a dimension or CSR approach in the context of Corporate Social Investment/ investing impulse by motive spectrum from "charity" to "efficiency" (Brilliant, 1998:299313). There are four models or CSR pattern that commonly implemented in Indonesian companies, which are (1) direct involvement, (2) through foundation or company social organization, (3) partnership, (4) support or join consortium. In direct involvement the company runs the CSR program by organizing the social activity or giving donation to society without any agency. For this task, a company usually assigns a senior official, like corporate secretary or public affair manager or a part of public relation duty. Through foundation or company social organization. The company establishes a foundation under a company or group.
This model is adopted from companies in modern countries. Usually, the company provides early fund, routine fund or eternal fund that can be used regularly for foundation activity. Through partnership, the company conducts CSR through cooperation with social organization/Non Government Organization (NGO), Government, University or mass media. The cooperation could be in funding or in conducting social activities. In support or join in consortium, the company establishes, become a member or support social organization which is founded for social purpose. Compared with other models, this pattern orientation is to give donation by means of a "development grant". The consortium or the organization actively makes network and develops the program as agreed. (Saidi, 2004:64-65)

A few months after the disaster in Jogjakarta I received a biscuit packaging named Biskiz Susu. On the package it is written "Bantuan dari United Nations World Food Programme Kerjasama Dengan Pemerintah Indonesia." (The Help from United Nations World Food Program in Collaboration with the Indonesian Government). There were logos of World Food Programme (WFP) and Biskiz Susu with a lion mascot. I noticed some unique information on this packaging, so I tried to analyze the design elements, like color, shape, brand, illustration/character, typography, and layout and then connect them with aspects like: the visual perception impact of packaging design and the importance of communicating Corporate Social Resposibility for the beneficiary and the contributors. For input information, I also discussed some consideration aspects of placing the contributor's identity on packaging.

The important and fundamental principles of packaging technology are to protect, to preserve, to contain and to inform. Principally, the purpose of packaging is to contain and to protect a product throughout its distribution and sale. Packages perform the primary purpose of containment and protection, but vary enormously in appearance, texture, graphic, shape, cost and structure. When designing a package, no single package is necessarily right or wrong but one might be considerably more appropriate than another (Denison, 1999).

Besides packaging, I found two other media that use by United Nations World Food Programme to promote their activities. That another two medias are website, and broshure. A website simulates the brand personality of a company. Its palette of engaging content, sound, movement and color creates a walking, talking interactive company experience. It's the next best thing to reality, and in 
some cases it's more efficient, more user friendly, and faster. Website are increasingly used as portals for media tools. From images to logos and message points, downloading from a ste allows employees to jump-start marketing and communications from anywhere in the field or around the world. (Wheeler, 2003:106). Broshure continue to be popular marketing and information tools. The best broshures invite readership since they easy to understand and user friendly. Designing a unified system ensures that the identity of the company is consistently presented and communicates familiarity to the existing customer (Wheeler, 2003:102).

\section{World Food Programme Activities}

WFP's Protracted Relief and Recovery Operation (PRRO) helps to achieve these goals - by providing nutritional assistance to vulnerable children and pregnant women. However, aid activities also provide recovery rations to the most vulnerable tsunami survivors, boost primary school attendance, encourage TB patients to finish their treatment, help people improve their livelihoods and assist communities to develop.

The Indonesian government has embraced ambitious targets for reducing the rates of malnutrition and maternal and child mortality by 2010 in line with the UN's Millenium Development Goals. About 845,000 beneficiaries are targeted. Specific activities include: nutritional Rehabilitation aid via local health centres. School Meals and TB assistance. In nutritional rehabilitation program, pregnant women and nursing mothers receive fortified noodles; children receive either fortified biscuits or fortified blended food (Greater Jakarta, East Java, NTT, NTB, south Sulawesi and Aceh \& Nias); School Meals- about 320,000 primary school students receive fortified biscuits in class every day to increase attendance and performance (Greater Jakarta, East Java, NTT, NTB and Aceh \& Nias); TB assistance-rice and fortified noodles to 105,000 TB patients and their families to encourage patients to finish their treatment regime and provide extra nutrition to help them fight the disease (Greater Jakarta, East Java, NTB, NTT and south Sulawesi).

\section{Methodology and Analysis}

I use the descriptive qualitative analysis to analysis the media. After collecting some datas through observation, literature study and web browsing, I try to analys the packaging design as the first and important media to communicate Corporate Social responsibility than I observe some media related to the program namely: website and broshure. In this reaserch I also analyse the graphic design elements in packaging design to find the importance of placing them to communicate Corporate Social Responsibility.

\section{Biskiz Susu Packaging Analysis}

In the case of Biskiz Susu product, The World Food Program (WFP) had ordered a large amount of processed foods from a local snack producer UNIBIS for urgent delivery. Foods, ready-to-eat foods in particular, were the most needed item for the Nias quake survivors. To show the sympathy, UNIBIS put 1.400 workers in extra hours and efforts to fulfill the order. UNIBIS, the largest biscuit-snack manufacturer of Sumatra, supplied emergency foods to the tsunami victim in Aceh in the past months. This time it contributed 2.5 tons of foods as a gift to Nias shortly after the quake. Yanuar Riwan, the UNIBIS owner-manager said the WFP directs foods made for surviving children and should be given special treatment. Accordingly, UNIBIS has added a new ingredientvitamin to the biscuits. Some 12,000 tons of vitamin-added biscuits would be made from April to June for WFP to be sent to Nias and Aceh. Meanwhile, information from Nias shows food has become the biggest challenge for the residents after the stabilization of the medical situation. However, with the connection of half of the island's $22 \mathrm{sub}$ districts by a repaired road system, government and international emergency foods had started to reach them, especially those in the deep south where there was little to eat for days and rice prices were shooting up by 50 percent. The food issue was the most serious for children. The emergency foods such as the nutritious WFP biscuits had help the children recovered well. (Xinhua News Agency, April 11, 2005). World Food Program distributed this product as donation for Aceh and Nias the first time, but in the process they also donated for Jogyakarta's earthquake victims.

Biskiz susu is a milk biscuit product for donation, packaged at 50 grams each. The packaging material made of flexible packaging. The FPA defines a flexible package as any package whose shape can be readily changed. Flexible packaging is utilized in a variety of fields - food and beverage, pet food, medical, cosmetics, health and beauty, and other consumer product. The food industry is a major user of flexible packaging. The variety of products to be packaged requires that a host of objectives be met. The objectives may or may not include: moisture barrier protection, oxygen barrier protection, fragrance and taste protection, puncture resistance, clarity, UV light repellency, seability, re- 
closeability. (Mosberg, 1989: 97). On the packaging, there is a big company logotype UNIBIS and logogram, the head of chef. Below the company logo, there is an information "Biscuit yang Difortifikasi Dengan Vitamin dan Mineral" (Vitamin and Mineral Fortified Biscuits). The packaging is also complete with Halal logo, Health Department (BPOM) license, expired date and name of the manufacturer. There is information that shows this product is not for sale. First, the typography clearly explains that this product is a donation from United Nation World Food Programme collaborating with the Indonesian Government. Second, there is flash information that this product is free (Gratis). Third, there is a World Food Programme logo besides the product brand; product character, photo and tag line "Penuh Nutrisi" (Full Nutrition). There are three illustrations of product brand along with character and product photo.

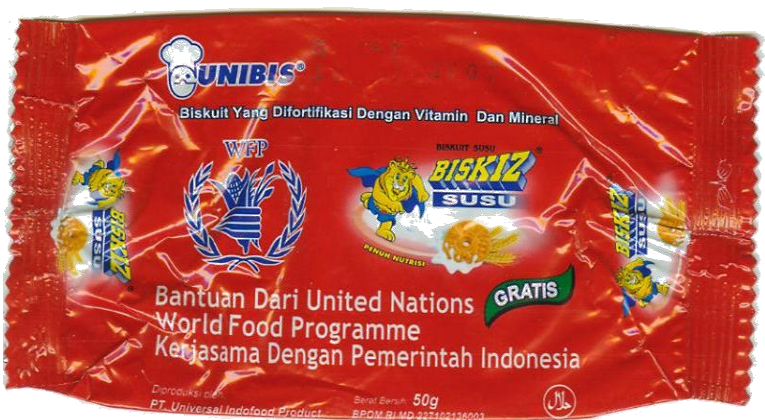

Figure 1. The Front-side design of Biskiz Susu Packaging

At the back of the packaging, there are general information like nutrition information, biscuit composition, storage suggestion and suggestion to consume ten biscuits every day. There is also information to not accept the product if the packaging is broken. Those information are printed like common biscuit product packaging, but without a barcode, because this product is not for sale. Basically, the packaging is made professionnally, like biscuit products for sale.

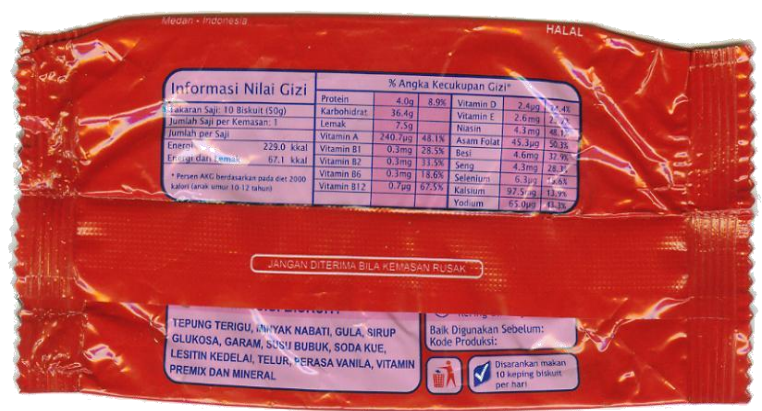

Figure 2. The Backside design of Biskiz Susu Packaging

\section{Media Analysis}

In collaboration with the Government, WFP has published a Food Insecurity Atlas of Indonesia and a Nutrition Map of Indonesia.

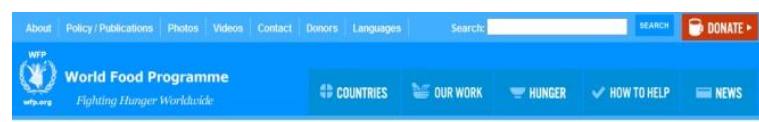

Countries
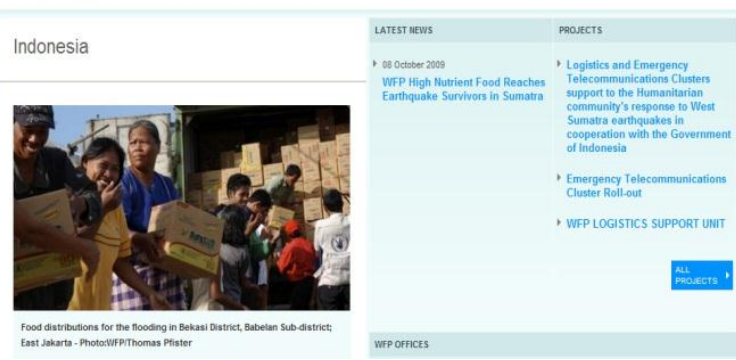

Figure 3. WFP Website Showing Food distributions for the flooding in Bekasi District, Babelan Sub-district; East Jakarta-Photo: WFP/Thomas Pfister

Besides informing their programme, WFP also try to collecting some donation. WFP need to corporate with some huge corporation. Broshure is one of the selected media to colect the donation. In the broshure, WFP show the product that they donate to the people who need. In this case, WFP try to help the malnutrision children in Indonesia. To show that the product is accepted by beneficiary, they need to show the packaging design. Through the graphic design like: color and logo, donatur will know the donated product.

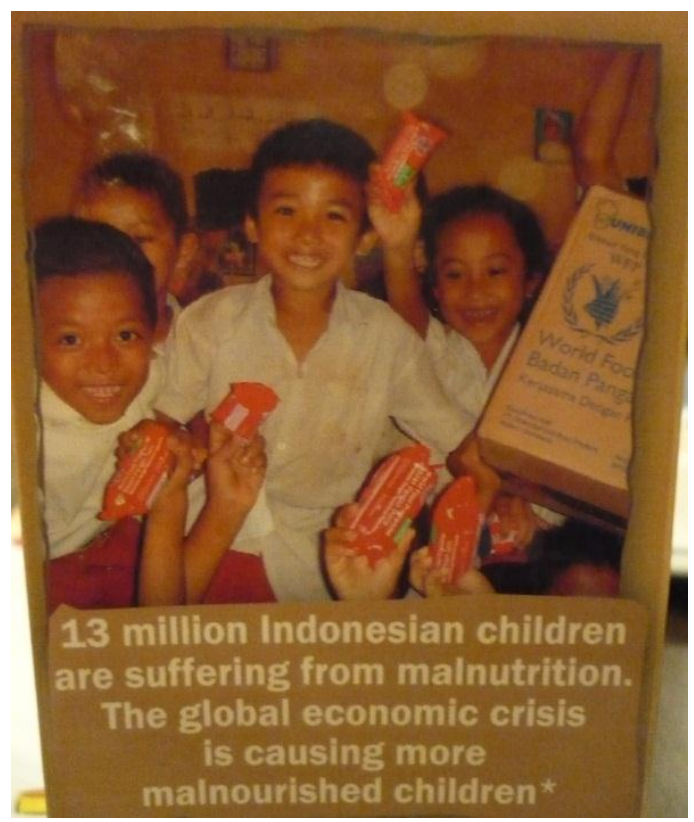

Figure 4. Packaging Design Photo Placing on Broshure 


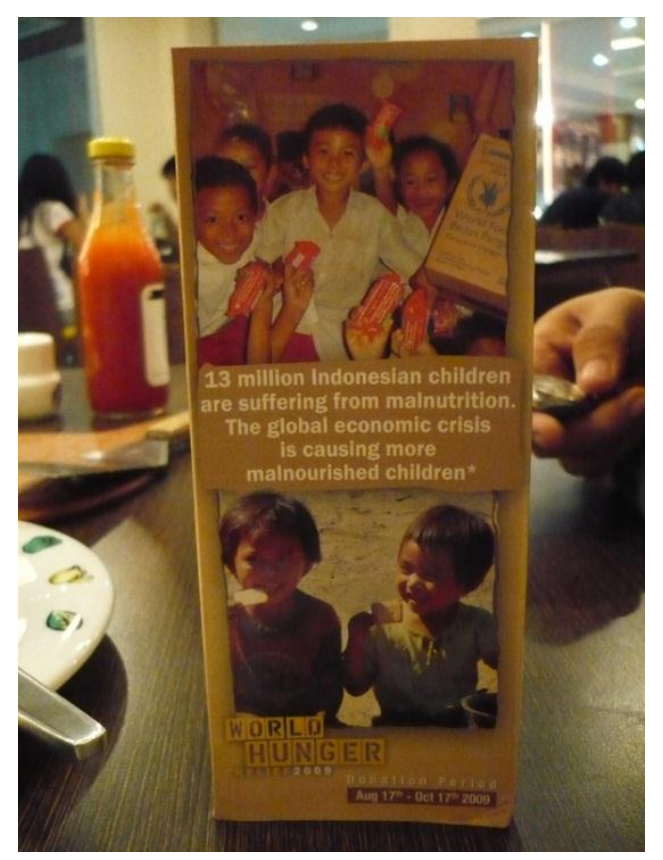

Figure 5. Broshure of WFP in One of the Famous Restaurant.

I found there are many media that the WFP use to promote their programme like: website, broshure and packaging design. All of the media integrated to one another. For examples all media have the logo of World Food Programme. Website of WFP containing the packaging of Biskiz Susu Carton Box packaging and broshure of WFP also having the picture of Biskiz Susu Packaging. I can say that packaging is an effective media to promote the WFP Programme and graphic design is an important element to communicate the Corporate Social Responsibility. By looking at the packaging design in each media, there will be an integration among the programme.

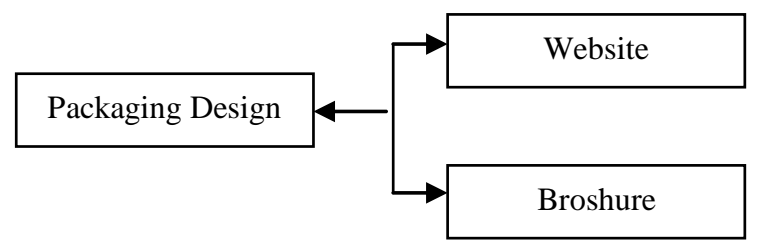

Figure 6. The integration of Packaging Design in the Offline and Online Media

\section{Discussion}

In this part of my paper I discuss about the visual perception impact of Biskiz Susu packaging design and the importance of communicating Corporate Social Responsibility.

Looking at the elements of packaging design, typography dominates in informing the donation of World Food Programme (WFP) and the invol- vement of government. The existence of WFP's logo and biskiz susu make people realize the organization's contribution of the product. Based on these two elements, there might be two perceptions of those who participate in this donation programme. First, people can think this help is only from WFP and the Indonesian Government. Second, based on the product brand, people may think that UNIBIS, the biscuit company, gives contribution in this donation. The printed typography and logos can give different perceptions about the contributor's identity.

The logo placement for United Nations, can function as a report or proof that they have done the social program in Indonesia. The beneficiary recognizes that United Nations through their World Food Programme has helped them cope with starvation and nutrition fulfillment. For the Indonesian government, this information is important to build a good image. This kind of information helps reduce the negative side of government, considering that there are a lot of complaints that the government is too slow in dealing with the disaster. Meanwhile, by placing the product's name and company logo, these activities are considered as Corporate Social Responsibility. In the case of Biskiz Susu, this program initiative came from the United Nations, but without the strong commitment and involvement of the company, the company logo and brand usually are not included in the packaging. The placement of the contributors' identities can be used to identify the distribution. It will help to reduce corruption in distribution. By giving the contributors' identity and free product information, hopefully producers will not sell the products and consumers will buy more carefully. Generally, free products do not have economic value. With the existing of contributors' information, contributors and related organizations can give the donation to the right target. In the storage process, the information helps contributors calculate distribution according to the beneficiary's condition and capacity besides limiting the misapplication by certain parties. The company logo also gives a strong impact to the beneficiary that this product is in high quality. Psychologically, the existence of the company logo makes the beneficiary feel safe in consuming the product.

The red color of the packaging gives a strong memorability of the product, and also with the lion character. The layout is also balanced and has been designed as similar as common biscuit products. Unfortunately, because of the similarity of color, brand name, and mascot, many of the beneficiaries think that Biskiz Susu is identical with other famous biscuit products. 


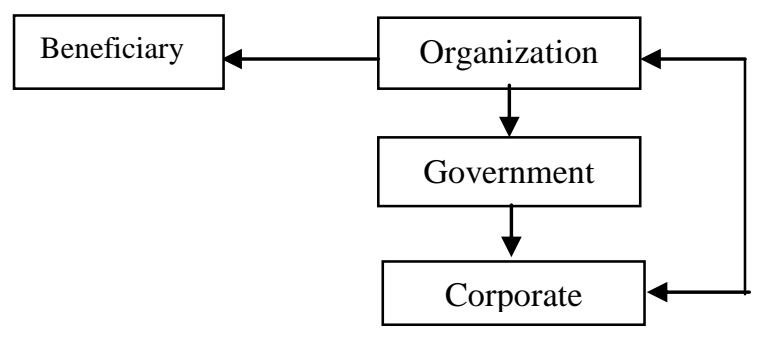

Figure 7. The Networking Model based on Graphic Elements Analysis

CSR provides an interesting way to build better brands. The challenge is to find the right balance between CSR and other brand values (Bruggenwirth, 2006:140). Bloom, Hoeffler, Keller and Basurto see "marketing initiatives containing a larger amount of social content having more positive effect on brand judgments and feelings than initiatives that are similar in size and scope but contain less social content. Social content means activities in the marketing initiatives that are meant to make tangible improvement to social welfare (Kotler, 2005:14). The placement of graphic design to identify donation is important. It brings many advantages tangible or intangible. The tangible advantages relate with the product selling, they could be achieved in quite a long period of time. Usually, the company expects that the beneficiary who received the donation can easily remember the product and the brand, so in the future after recovery they will do some purchasing. Intangible advantages can be achieve in quite a short time, like improved brand image of the product and good image of United Nations' World Food Programme and the government.

\begin{tabular}{|c|c|c|}
\hline $\begin{array}{l}\text { Organisation/ } \\
\text { Government }\end{array}$ & Corporate & \\
\hline $\begin{array}{l}\text { Emotional value } \\
\text { (Good image) }\end{array}$ & $\begin{array}{l}\text { Psychological } \\
\text { value (Safe } \\
\text { foeling) }\end{array}$ & Intangible \\
\hline $\begin{array}{c}\text { Control } \\
\text { (Distribution) }\end{array}$ & $\begin{array}{l}\text { Benefit } \\
\text { (Increased } \\
\text { Sales) }\end{array}$ & Tangible \\
\hline
\end{tabular}

Figure 8. The Importance of Communicating Corporate Social Responsibility

\section{Aspects to Consider}

There are many aspects to consider before using packaging as a medium to communicate Corporate
Social Responsibility (CSR), like: the quantity of the product, the printing budget, the duration of the social activity, and what kind of graphic design elements should be placed on packaging design based on the contribution of the contributor's participation.

Flexible packaging needs large quantities to print. The larger the quantity, the cheaper the price. Before deciding to print, they have to make sure how many products will be donated based on how many people will receive the donation and how long the program will be held. In the case of Biskiz Susu product, this product has been delivered to help Aceh, Nias at first and then Jogjakarta earthquake victims.

The duration of distribution must be calculated and planned well. The length of product expiration dates determines the packaging quality. The longer the distribution time, the packaging needs to be thicker and which means additional cost. At the emergency situation, timing is very important. People need help as soon as possible. The company must consider the length of the printing process, the product packaging and delivery. In the case of food product, the expiration date must be a main consideration. There are many donations expire before they are distributed or received by the beneficiary. Choosing a local company could reduce the time of distribution.

The placement of the contributor's identity can be used to identify the distribution. It helps to reduce the corruption in distribution. For the graphic design elements, whenever there are many participants in the donation, the identity of donors must be placed according to their contribution. The company logo, brand, illustration, character or the typography can be the graphic element to identify CSR. The beneficiary will feel safe if the packaging and the information are made professionally. If the packaging is made as similar as to products sold in the stores, the company could benefit from the purchases by the beneficiary in the future.

\section{Conclusion and Sugestion}

Graphic design is not only fuction to inform a product but also elements to inllustrate Corporate Social Responsibility. Packaging design functions have been developed to not only for protection, preservation, containment and informing about the product, but packaging could be a medium to communicate Corporate Social Responsibility. There are many ways to deliver the good will of an organization or company. For the UNWFP, the placement of the contributor's identity can identify the place of distribution, the organization or the 
beneficiary who received it. It helps to reduce corruption, wrong distribution, stockpiling and the risk the wrong people receiving the donation. For the government, it will show their involvement and built a good image of the government. For the company, the placement of their logo and brand could identify the contribution of a corporation. For the beneficiary, the existence of the brand, make them feel safe to consume the product. They could remember the product's name and the company can improve their brand image, so hopefully the beneficiary will become future consumer.

There are many ways that a company can implement CSR, like: direct involvement, through a foundation or a social organization, through partnership and by joining in consortium. This is an interesting phenomenon that the activity of UNWFP can develop social activity in Indonesia, especially having a partner with a local company. In the case of Biskiz Susu product, by supporting the World Food Programme, this local company has a big opportunity to get involved in this program, and they can improve their brand image by developing their CSR.

There are many aspects to consider in using packaging, like: the quantity of the product, the printing budget, the duration of the social activity and the design. Graphic Design elements in packaging play important roles in communicating CSR. The graphic elements must be designed thoroughly, because every element can give differrent perceptions about the contributor's identity. CSR gives benefit to an organization, a government and or a company, in a short or long period of time. For the company, it is reasonable expecting profit in the future, but not ignoring the cause. Even though there are many aspects to consider, packaging design is one of the recommended medium to communicate Corporate Social Responsibility. It gives many advantages for those who participate in the program. By implementing the consistency of graphic design and showing the packaging design in other media namely website and broshure, there will be an integration among the WFP programme.

\section{References}

Brilliant Eleanor L. Dan Kimberlee A. Rice. (1988). "Influencing Corporate Philantropy" dalam Gary M. Gould dan Michael L. Smith (eds), Social Work in the Workplace. New York: Springer Publishing Co.
Bruggenwirth, Bart. (2006). The CSR Brand Positioning Grid. Management Models for Corporate Social Resposibility. Jan Jonker and Marco de Witte editors.Germany:Springer.

BBC News.(25 June 2005). Tsunami aid went to the richest'.20 November 2008. http://news. bbc.co.uk/2/hi/south_asia/4621365.stm

Denison, Edward \& Cawthray, Richard.(1999). Packaging Prototype. USA: RotoVision SA.

Fahrini Cutti. (2007). Surat Anak Aceh. 12 November 2008. Kumpulan Jurnal. http://paul02583. wordpress.com/2007/12/

Grayson, David and Hodges Adrian ((2004). Corporate Social Opportunity.UK: Greenleaf Publishing.

Kotler, Philip. (2005). Corporate Social Responsibility Doing the Most Good for your Company and your Cause. New Jersey:John Wiley \& Sons, Inc.

Mosberg, Stewart. (1989). Design in Motion Packaging. New York: PBC International, Inc.

Nias Earthquake. (2005). http://www.ifrc.org/docs/ appeals/rpts05/IDeq30030503.pdf. 30 March 2005.

Nugroho, Banu Tri. (2006). Menambah Daya Tarik Melalui Keindahan, 20 Nopember 2008. http://mipa.uns.ac.id/ scienta/tutorial.doc

Saidi, Zaim dan Hamid Abidin. (2004). Menjadi Bangsa Pemurah: Wacana dan Praktek Kedermawanan Sosial di Indonesia. Jakarta: Piramedia.

The May 27, 2006. Jogjakarta Earthquake. 20 November 2008. http://www.seis.nagoyau. ac.jp/irwan/jogjaeq/jogjaeq.html

Wheeler, Alina. (2003). Designing Brand Identity. A Complete Guide to Creating, Building, and Maintaining Strong Brands. USA: John Wiley \& Sons, Inc.

Wineberg, Danette and Philip H. Rudolph. (May 2004)."Corporate Social Responsibility-What Every In House Counsel Should Know", dalam ACC Docket.

World Food Programme. (2010). Fighting Hunger Worldwide. 12 January 2010. http://www. wfp.org/countries/Indonesia

Xinhua News Agency. (April, 11, 2005). WFP Supplies Emergency Food To Quake-Hit Nias. 20 November 2008. http://www.china.org.cn/ english/features/tsunami_relief/125434.htm

Zilenziger, J.Rodman. (1996). Label and Narrow Web, Rodman Publication Online, 21 Oktober 2008. http://www.labelandnarrowweb.com/ october021.htm 